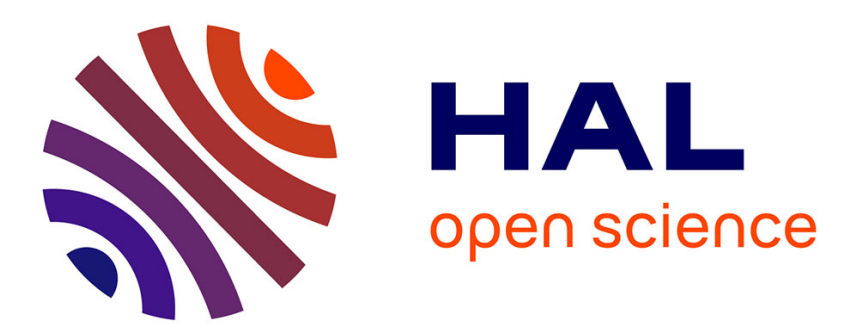

\title{
Evaluation of attractant flavours for use in oral vaccine baits for badgers ()
}

David J. Kelly, Leigh A. L. Corner, Eamonn Gormley, Denise Murphy, Eamon

Costello, Frank E. Aldwell, Nicola M. Marples

\section{- To cite this version:}

David J. Kelly, Leigh A. L. Corner, Eamonn Gormley, Denise Murphy, Eamon Costello, et al.. Evaluation of attractant flavours for use in oral vaccine baits for badgers (). European Journal of Wildlife Research, 2011, 57 (4), pp.767-774. 10.1007/s10344-010-0485-7 . hal-00656345

\section{HAL Id: hal-00656345 \\ https://hal.science/hal-00656345}

Submitted on 4 Jan 2012

HAL is a multi-disciplinary open access archive for the deposit and dissemination of scientific research documents, whether they are published or not. The documents may come from teaching and research institutions in France or abroad, or from public or private research centers.
L'archive ouverte pluridisciplinaire HAL, est destinée au dépôt et à la diffusion de documents scientifiques de niveau recherche, publiés ou non, émanant des établissements d'enseignement et de recherche français ou étrangers, des laboratoires publics ou privés. 


\title{
Evaluation of attractant flavours for use in oral vaccine baits for badgers (Meles meles)
}

\author{
David J. Kelly • Leigh A. L. Corner • \\ Eamonn Gormley • Denise Murphy • Eamon Costello • \\ Frank E. Aldwell • Nicola M. Marples
}

Received: 12 May 2010/Revised: 1 December 2010 /Accepted: 2 December 2010 /Published online: 4 January 2011

(C) Springer-Verlag 2010

\begin{abstract}
European badgers (Meles meles) are a wildlife reservoir for Mycobacterium bovis infection (tuberculosis) in Ireland and the UK and are implicated in the transmission of infection to livestock. Vaccination of badgers with the human BCG vaccine (Bacille Calmette Guerin) is considered as an important strategy to reduce the burden of disease in this species, and a pragmatic approach is likely to involve oral vaccination. In this study, we evaluated nine different flavours for use as attractants in a prototype oral vaccine bait for European badgers (M. meles): aniseed, apple, cocoa powder, carob powder, curry, fish, garlic, peanut and strawberry. The bait matrix was composed of a natural lipid formulation, developed as a vehicle for oral vaccination against tuberculosis in wildlife. A 'food for work' paradigm was employed during the trials to ensure the animals were actively seeking the baits. The trials showed carob and cocoa powders were equally attractive
\end{abstract}

Communicated by C. Gortázar

D. J. Kelly $(\bowtie) \cdot$ N. M. Marples

Department of Zoology, School of Natural Sciences,

Trinity College,

Dublin 2, Ireland

e-mail: djkelly@tcd.ie

L. A. L. Corner · E. Gormley · D. Murphy

School of Agriculture, Food Science \& Veterinary Medicine,

University College Dublin,

Dublin 4, Ireland

E. Costello

Department of Agriculture, Fisheries and Food, Central Veterinary

Research Laboratory,

Celbridge, County Kildare, Ireland

F. E. Aldwell

Centre for Innovation, University of Otago,

87 St David Street, Box 56, Dunedin, New Zealand and more attractive than any of the other candidates. Carob and cocoa show potential as bait attractants for badgers and might form part of a novel vaccine delivery system.

Keywords Attractants $\cdot$ Carob - European badger $\cdot$ Meles meles . Oral vaccine $\cdot$ Bovine tuberculosis

\section{Introduction}

Mycobacterium bovis infection is endemic in wildlife populations in many countries, e.g. brushtail possums (Trichosurus vulpecula) in New Zealand (Morris et al. 1994), white-tailed deer (Odocoileus virginianus) in USA (Schmitt et al. 1997), wild boar (Sus scrofa) in Spain (Naranjo et al. 2007) and badgers (Meles meles) in Ireland and the UK (Clifton-Hadley et al. 1993; Gormley and Costello 2003; Griffin et al. 2005).

Bovine tuberculosis (M. bovis infection in animals, BTB) is a significant disease of cattle and wildlife in many countries, and as a zoonotic infection, M. bovis has the potential for transmission across species barriers to susceptible hosts including humans (Ali et al. 2009; Doran et al. 2009). Although the badger is protected under Irish and European law, where an epidemiological investigation implicates badgers in the transmission of infection to cattle, they can be culled in the vicinity of affected farms (More and Good 2006; O'Keeffe 2006). It is unlikely that limited culling alone will eradicate infection from the Irish badger population, and it is not considered an ecologically sustainable, long-term approach (Griffin et al. 2005).

An oral vaccination program may offer an alternative control strategy for BTB in badgers (Gormley and Collins 2000). Vaccination of badgers with BCG, the only vaccine licensed for tuberculosis in humans, has been shown to 
induce immune protection in badgers when delivered by a variety of routes (Corner et al. 2007; Lesellier et al. 2009), and it has been proven to be safe in captive badger studies (Lesellier et al. 2006). If vaccination is shown to be effective in wild populations, it may be incorporated as a key element in a long-term control strategy (Gormley and Collins 2000). Oral vaccination is an attractive proposition as it is a relatively inexpensive technique and relies on a simple delivery system (Pouwels et al. 1998). Oral baits have been used to deliver vaccines (Slate et al. 2009), contraceptives (Cooper and Larsen 2006) and toxic chemicals (McDowell et al. 2006) to wildlife.

Given the difficulties in trying to achieve high levels of vaccine coverage in wildlife populations, numerous studies have been conducted that have incorporated attractants into baits for wildlife to increase levels of consumption.

A wide range of products have been used to increase the attractiveness of baits for wild mammals; strawberry (cotton wool impregnated with a strawberry flavouring) has been used successfully as an attractant for feral swine (Campbell and Long 2009), cinnamon-truffle powder (as a bait additive) for feral swine piglets (Ballesteros et al. 2009), apple (both apple juice and apple odour) for white-tailed deer (Bean and Mason 1995), marshmallow (as a bait flavouring) for gray foxes (Steelman et al. 2000) and cinnamon oil and anise oil (as bait additives) for brushtail possums (Morgan 1990; Aldwell et al. 2003a). Fish products have worked well as attractants for raccoons (Linhart et al. 1994), skunks (Jojola et al. 2007), mongooses (Creekmore et al. 1994) and red foxes (Smith and Woods 2007), whereas offal has proved a useful attractant for dogs (Estrada et al. 2001) and coyotes (Stolzenburg and Howard 1989). Peanuts, often mixed with syrup, have frequently been used to bait badger traps (Southey et al. 2002). Although meat-based baits have been used to attract mustelids and carnivores (Matter et al. 1995; Estrada et al. 2001; Smith and Woods 2007), their use has been discontinued due to concerns relating to transmissible spongiform encephalopathies (TSEs) (Novakofski et al. 2005).

Uptake of baits is influenced both by their attractiveness and their palatability: attractiveness will bring animals to the baits and palatability will ensure consumption. Attractiveness and palatability can be influenced by the presentation, construction and composition of the baits. Recent developments in an oral vaccine for tuberculosis (Aldwell et al. 2003a, b; Cross et al. 2009; Tompkins et al. 2009) have resulted in the production of solid lipid baits that can be used to encapsulate live BCG bacilli. When delivered by the oral route, lipid-formulated BCG has been shown to induce protection in brushtail possums (Tompkins et al. 2009) and badgers (Corner et al. 2010). We used lipid baits in the current study with captive badgers to test the relative attractiveness of nine flavours when presented in a prototype oral lipid bait formulation.

\section{Methods}

Study area

The studies with captive badgers were conducted in a compound designed for holding badgers for bovine tuberculosis research. Our studies ran between May and June 2008.

\section{Attractant selection}

From the analysis of results generated in other studies (including studies on mammal species other than badgers), we selected a range of nine attractants representing animal, vegetable and spice flavours: anise (Aldwell et al. 2003b), apple (Bean and Mason 1995), carob (Craig and Nguyen 1984), cocoa (Cross et al. 2009), curry (Morgan et al. 1995), fish (Smith and Woods 2007), garlic (Marsh 1988), peanut (Southey et al. 2002) and strawberry (Takeuchi 2007).

\section{Bait preparation}

The attractants used were: liquid aniseed flavouring ${ }^{1}$, liquid apple flavouring (Richworth Baits, Surrey, UK), carob powder (Hambledon Herbs, Wiltshire, UK), cocoa powder (Cadbury Ireland Ltd, Coolock, Dublin), liquid curry flavouring (Richworth Baits, Surrey, UK), blended fish oil (Nutrabaits, www.nutrabits.com), garlic oil (Nutrabaits, www.nutrabits.com), liquid peanut flavouring (Richworth Baits, Surrey, UK) and liquid strawberry flavour (Richworth Baits, Surrey, UK). The attractants were mixed into the molten $\left(38^{\circ} \mathrm{C}\right)$, edible lipid matrix (Lipid-PK, Aldwell et al. $2003 \mathrm{~b}, 2005)$ at the following rates: liquid flavourings, $1.2 \%$ $v / v$; fish oil, $1.2 \% v / v$; garlic oil, $0.4 \% v / v$; powders, $0.8 \%$ $w / w$. The bait formulations were mixed thoroughly, refrigerated and cut into small blocks $\left(\sim 1.2 \mathrm{~cm}^{3}\right)$ once they had solidified. These baits were stored at $6-8^{\circ} \mathrm{C}$.

\section{Study animals}

The badgers $(n=17)$ were held in seven outdoor pens (each $\sim 200 \mathrm{~m}^{2}$ with earthen floors covered in grass and shrubs) in groups of 1-4 animals. They had been in the pens for several months prior to the start of the

\footnotetext{
${ }^{1}$ Flavourings were not essential oils and had water-based and oil-based components.
} 
presentations. The pens were constructed with standard chain-link fencing, buried to a depth of $0.5 \mathrm{~m}$. The fences had an overhanging rim along the interior surface to prevent the badgers from climbing out of the pens but were otherwise uncovered. The badgers were fed daily on a diet of high energy biscuits (Racer ${ }^{\mathrm{TM}}$ Connolly's Red Mills, Goresbridge, Ireland) and shelled peanuts (Murtagh $\&$ Sons, Ashbourne, Ireland) (total mixed ration $\sim 450 \mathrm{~g}$ per badger per day). Access to water was ad libitum.

Animal care

All work with the captive badgers was carried out under license from the Department of Health and Children (B100/ 3187) under the regulations of the Cruelty To Animals Act, 1876, as amended by European Communities Regulations: S.I. 2002/566, 2005/613. Ethical approval for working with captive badgers was obtained from the Animal Research Ethics Committee (University College Dublin).

\section{Study design}

Data were recorded at the level of pens, as it was not possible to record the behaviour of individual animals. A preliminary study (see below), where all pens were offered the same three baits under novel tiles, was conducted to establish the viability of the experimental presentation format. This study provided clear evidence that badgers were willing to seek out food placed under tiles. In the main study, designed to test the comparative attractiveness of nine different odours, an incomplete Latin square design was used to present the attractants (Table 1). The attractants were presented in groups of three (each under a separate tile). Each attractant was offered to a pen on three separate occasions (once during each iteration). Different combinations of attractants were presented to each pen at each iteration, such that no two attractants were offered together on more than one occasion.

Presentation of attractants

Preliminary study This study used all of the animals subsequently included in the main study. Badgers were presented with shelled peanuts, raisins or broken biscuits, placed under ceramic tiles (area $\sim 0.06 \mathrm{~m}^{2}$, weight $\sim 2.3 \mathrm{~kg}$ ). The tiles were considered to be sufficiently heavy to prevent access from non-target species (e.g. birds (Corvus spp.) and rats (Rattus norvegicus)). Movement of the tiles was considered to be evidence of badger activity.

Main study At each presentation, each pen was offered three different attractants (two pieces of bait covered by a tile) and a control tile (a tile covering a paper marker without bait); giving a total of four tiles per pen at each presentation. This allowed a comparison of the behaviour of the social group in each pen towards the attractants, as well as towards the tiles.

In order to offer each pen all nine attractants, three separate presentations were made (see Fig. 1). These presentations were made on alternate days to limit habituation of the animals. Each set of three presentations was termed an iteration. The trial consisted of three such iterations. Iterations were conducted on alternate weeks to limit habituation. The baits were placed in position in the late evening as badgers are nocturnal feeders, and the tiles were examined in the early morning.

\section{Assessment of behaviour}

The morning after a presentation, all tiles were examined for evidence of badger activity. The bait was deemed to
Table 1 Blocking design for presentation of nine attractants to seven pens of badgers ( $1=$ aniseed flavouring, $2=$ apple flavouring, $3=$ carob powder, $4=$ cocoa powder, $5=$ curry flavouring, $6=$ fish oil, $7=$ garlic oil, $8=$ peanut flavouring, $9=$ strawberry flavouring)

\begin{tabular}{lccccccc}
\hline & Pen 1 & Pen 2 & Pen 3 & Pen 4 & Pen 5 & Pen 6 & Pen 7 \\
\hline First iteration & & & & & & & \\
Day 1 & 123 & 456 & 789 & 123 & 456 & 789 & 123 \\
Day 2 & 456 & 789 & 123 & 456 & 789 & 123 & 456 \\
Day 3 & 789 & 123 & 456 & 789 & 123 & 456 & 789 \\
Second iteration & & & & & & & \\
Day 1 & 147 & 258 & 369 & 147 & 258 & 369 & 147 \\
Day 2 & 258 & 369 & 147 & 258 & 369 & 147 & 258 \\
Day 3 & 369 & 147 & 258 & 369 & 147 & 258 & 369 \\
Third iteration & & & & & & & \\
Day 1 & 159 & 267 & 348 & 159 & 267 & 348 & 159 \\
Day 2 & 267 & 348 & 159 & 267 & 348 & 159 & 267 \\
Day 3 & 348 & 159 & 267 & 348 & 159 & 267 & 348 \\
\hline
\end{tabular}


Fig. 1 Investigation scores of baits by seven pens of captive badgers. Values given are the totals of the seven pens for each iteration as well as the average value for the three iterations. The dotted line indicates the mean investigation score for all baits across all iterations (0.47)

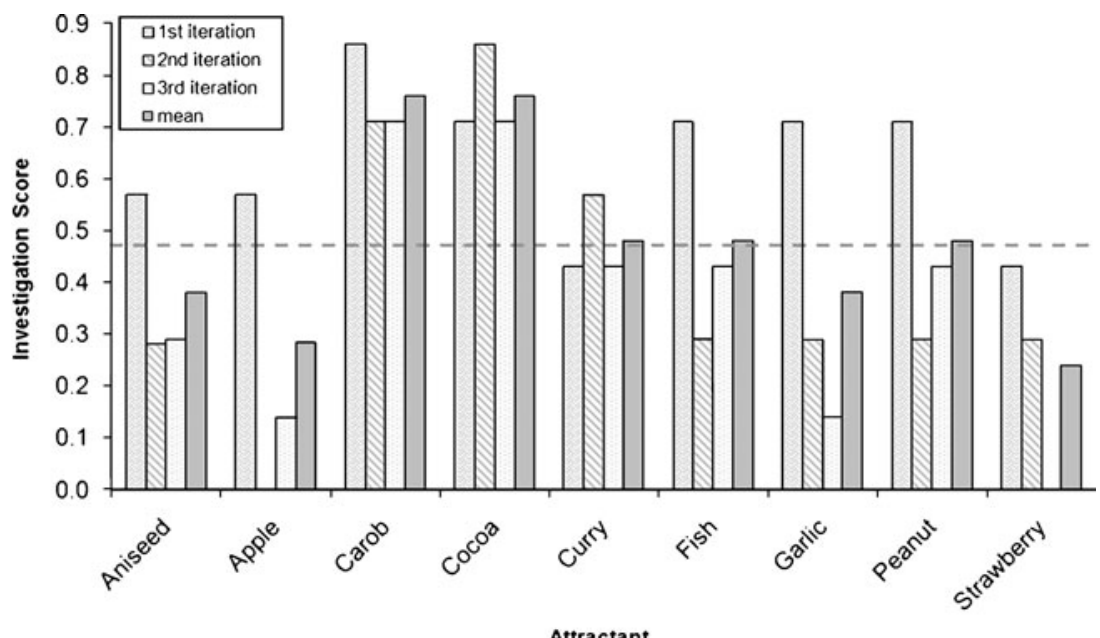

Attractant have been investigated if the tile had been moved from its original position and, after careful examination of the ground underneath, and in the vicinity of the tile, the baits were deemed to have been removed (by badgers) if no baits were present.

\section{Statistical analysis}

The blocked design was such that different pens received the baits in different orders (Table 1). To include this information in the analyses, a variable, order, was added.

Investigation for each attractant at each presentation was scored as either 1 or 0 . The investigation data were analysed with a linear mixed effects model using a logit function with the assumption that the observed data were binomially distributed. The analyses were run in $\mathrm{R}$ v2.9.1 (R Foundation for Statistical Computing, Vienna, Austria) using the function lmer contained in the package lme4. The variables pen and time (iteration and/or order) were included as random factors, while attractant was included as a fixed factor. Time effects were investigated in a nested manner (nesting cycle within order; a facility within the lmer function) as well as independently. Attractant (using reactions towards the fish attractant for reference) was used as a fixed factor. Fish was chosen as the reference attractant because it was the attractant with the highest average investigation score after carob and cocoa. Parameter effects in the mixed effects model are presented as $P$ values. As the sample size was relatively large (a total of 189 presentations), AIC (Akaike's Information Criterion) values, rather than the small sample-corrected alternatives (AICc), were used in this instance. A similar lmer model was used to analyse removal of the baits.

A third lmer model was used to analyse the frequency with which badgers investigated the control tiles. In this analysis, pen, order and experience were used as variables. Experience was an integer; $1=$ first encounter with control tiles, $2=$ second encounter, et cetera. Iteration was not used in this analysis, as control tiles were presented on multiple occasions in a single iteration of the trial (i.e. each pen was presented with a control tile in addition to the three attractants during each iteration). In this case, the model consisted of a relatively small sample size (a total of 42 presentations), so AICc were used for comparisons.

\section{Results}

Preliminary study

This study demonstrated that badgers were willing to move the tiles to gain access to the food items beneath. On a number of occasions ( 4 of 62 presentations), the tiles were moved, but not all the food was removed from beneath it.

Control tiles (placed outside the badger enclosures) were placed across obvious rat runs or in prominent positions (to encourage access by crows). None of the food presented under control tiles showed indications of investigation or removal.

Main study

There were three broad levels of investigation of the attractants (Fig. 1). These investigation scores are considered to be a good proxy for the attractiveness of the baits. Carob and cocoa baits were the most frequently investigated, with an average score of 0.76 , approximately $50 \%$ greater than the overall average investigation score $(0.47)$ for all baits. Curry, fish and peanut baits had lower levels of investigation with average scores of 0.48 , and the remaining attractants all had average scores of $\leq 0.38$, at least $33 \%$ 
lower than the overall investigation score. The maximal model for attractant investigation gave primary importance to "pen" and "iteration", although sub-maximal models (with AIC weights $>0.1$ ) also included "order". Comparisons of the attractants in the maximal model showed carob and cocoa baits to have been more frequently investigated than fish baits $(P<0.05$ in both cases; $\mathrm{AIC}=221.4$, AIC weight $=0.62$; Table 2 ).

Like investigation, there were three broad levels of removal of the attractants (Fig. 2). The grouping for removal scores was similar to that for investigation scores, with carob and cocoa baits being the most frequently removed (0.76). Removal scores were generally lower than investigation scores. The maximal model for attractant removal gave primary importance to "pen" and "iteration", although sub-maximal models (with AIC weights $>0.1$ ) also included "order". Comparisons of the attractants in the maximal model showed carob and cocoa baits to be removed more frequently than fish baits and strawberry baits to be removed less frequently than fish baits $(P<0.05$ in all cases; $\mathrm{AIC}=223.7$, AIC weight $=0.54$; Table 3).

The maximal model for control tile investigation (Fig. 3) gave primary importance to "experience" and "pen" (AICc $=41.39$, AICc weight $=0.82, n=42)$ and showed control tiles were investigated more frequently on their first encounter than on their second encounter $(P<$ $0.05)$. No control tiles were investigated during the fifth and sixth encounters.

\section{Discussion}

Of the nine candidate attractants tested in this study, carob and cocoa were the most frequently investigated and removed. The baits containing carob and cocoa attractants were investigated and removed on over $75 \%$ of the

Table 2 Maximal model for investigation of nine attractants by seven pens of badgers, using fish oil as the control

\begin{tabular}{lrll}
\hline & Estimate & SE & $P$ value \\
\hline Intercept (fish) & -0.204 & 0.91 & - \\
Aniseed & -0.551 & 0.73 & - \\
Apple & -1.138 & 0.76 & - \\
Carob & 1.826 & 0.81 & $<0.05$ \\
Cocoa & 1.826 & 0.81 & $<0.05$ \\
Curry & 0.000 & 0.72 & - \\
Garlic & -0.551 & 0.73 & - \\
Peanut & 0.000 & 0.72 & - \\
Strawberry & -1.463 & 0.78 & - \\
\hline
\end{tabular}

Parameter estimates (expressed as log-odds), associated standard error of the estimates and $P$ values are given for each treatment $(N=189)$ presentations across the three iterations of the study. The next highest scoring attractant bait (fish oil) was investigated and removed on only $48 \%$ of presentations.

A successful bait attractant will encourage the target animal to investigate the area where it is located and may well contribute towards the consumption of the bait, once found. Carob and cocoa were the most successful attractants in this investigation. There were a number of attractants which showed a disparity between the investigation and removal scores. It is unclear if these uneaten baits were disturbed while the badgers were searching for more preferred flavours. However, there were clearly times when baits were uncovered by badgers but left uneaten.

While we have been careful to record the baits as removed, rather than consumed by the badgers, the evidence from the control tiles in the preliminary study suggests that non-target animals were not gaining access to the baits. The disparity between investigation and removal scores suggests that the lipid baits were not considered attractive by non-target species. While we have no photographic record of the activity of the badgers in the enclosures, we believe that all removed baits were removed and consumed by badgers. Subsequent presentation studies with wild badgers (unpublished data) have shown lipid baits to be treated as valuable prey items.

We observed variation in the investigation patterns of badgers to the different attractants across iterations (Fig. 1). Some attractants were investigated consistently (carob, cocoa and curry), while others showed a changing pattern of investigation. Several attractants were investigated and/ or removed to a progressively decreasing extent. This is a pattern indicative of learning and memory by the badgers. Such a pattern was also clearly apparent in the investigation of the control tiles (Fig. 3).

All badgers learned, after four presentations, that the lack of an attractant cue (presumably odour) signalled the absence of a food reward. There were no signs of investigation of control tiles on their fifth and sixth presentations (Fig. 3). Where this pattern of declining investigation was found for baits containing attractants, it suggests that those baits were being classified as unattractive or were failing to provide an adequate food reward. By extension, it is possible that those baits showing higher levels of investigation over the three iterations had been learned and remembered as preferred food rewards. Apple, garlic and strawberry attractants all showed steeply decreasing patterns of investigation across the three iterations of the study (Fig. 1). This was unexpected, as apples and strawberries are known to be consumed by wild badgers (Boesi and Biancardi 2002; Takeuchi 2007). Baits were freshly prepared for each iteration, so neither chemical dispersal nor degeneration can explain this effect. 
Fig. 2 Removal scores of baits by seven pens of captive badgers. Values given are the totals of the seven pens for each iteration as well as the average value for the three iterations. The dotted line indicates the mean investigation score for all baits across all iterations $(0.41)$

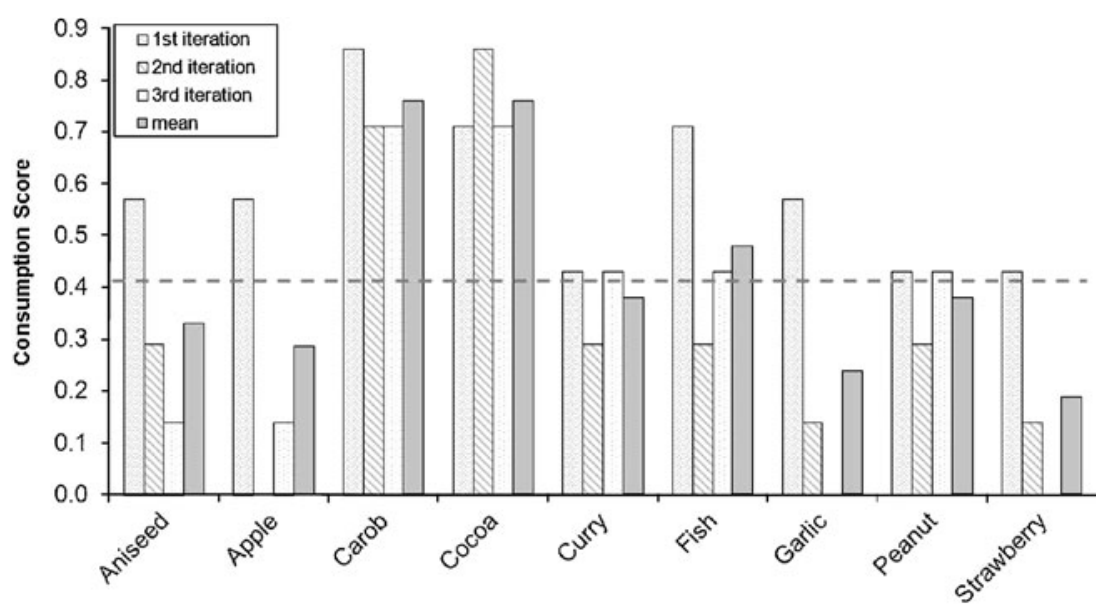

Attractant
The concentrations of the attractants used in this study were selected on the basis of a review of the literature and communications with those conducting similar studies elsewhere. Concentrations chosen were considered as moderate. We noted the experience of UK researchers, who reported rejection by badgers of baits flavoured with aniseed oil where the concentration of the oil $(1 \% w / w)$ was ten times that favoured by New Zealand workers $(0.1 \% w / w)$ working with brushtail possums (FE Aldwell, personal communication). It is unclear whether stronger or weaker concentrations of either carob or cocoa would have altered their attractiveness as observed in this study. Investigations into concentration effects may be undertaken in future studies.

Meat baits using mammalian tissues have traditionally been used for carnivores. However, they are now considered unacceptable because of concerns regarding TSEs. As

Table 3 Maximal model for removal of nine attractants by seven pens of badgers, using fish oil as the control

\begin{tabular}{llll}
\hline & Estimate & SE & $P$ value \\
\hline Intercept (fish) & -0.193 & 0.77 & - \\
Aniseed & -1.342 & 0.75 & - \\
Apple & -1.037 & 0.72 & - \\
Carob & 1.697 & 0.77 & $<0.05$ \\
Cocoa & 1.697 & 0.77 & $<0.05$ \\
Curry & -0.491 & 0.70 & - \\
Garlic & -0.747 & 0.71 & - \\
Peanut & -0.491 & 0.70 & - \\
Strawberry & -1.684 & 0.78 & $<0.05$ \\
\hline
\end{tabular}

Parameter estimates (expressed as log-odds), associated standard error of the estimates and $P$ values are given for each treatment $(N=189)$ an alternative, fish-meal baits have proved attractive for a range of carnivores: foxes (Smith and Woods 2007), raccoons (Roscoe et al. 1998), dogs (Corn et al. 2003), skunks (Jojola et al. 2007) and badgers (Southey et al. 2002). In this study, fish oil was not as attractive to badgers as either carob or cocoa.

Although equally as attractive as carob, concerns have been raised regarding the potential toxicity of cocoa. If badgers consume very large quantities of chocolate (cocoa), the constituent methylxanthines may induce fatal intoxication (Jansson et al. 2001). As methylxanthines pose similar dangers to other wildlife (Gunning 1950; Gartrell and Reid 2007) and pets (Gans et al. 1980; Bonagura and Twedt 2008), cocoa may be an unsuitable constituent for oral vaccine baits. As carob contains few or no methylxanthines, it does not pose a similar risk (Craig and Nguyen 1984). Therefore, carob might be a more suitable additive for an oral vaccine bait for badgers. Despite the clearly attractive nature of carob, its inclusion in oral vaccine baits will depend on how it affects BCG viability if it is in direct

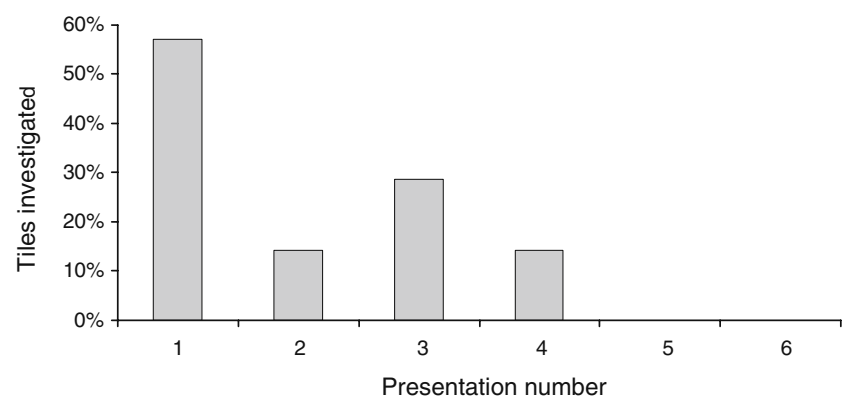

Fig. 3 Investigation scores for the control tiles (unbaited) by seven pens of captive badgers. Values given are the percentages of the pens showing evidence of investigation at each presentation 
contact with the live vaccine (Tassou et al. 1997). Nevertheless, the present study has clearly demonstrated the potential of carob as an effective attractant for badgers.

Acknowledgments We thank A. L. Jackson and C. J. Tanner for advice on statistical techniques and two anonymous referees for their comments on an earlier draft of this manuscript. DJK was supported by a grant from the Irish Department of Agriculture, Fisheries and Food. The contributions of EG, LALC and DM were funded by FP7 TB-Step (Strategies for the Eradication of Bovine Tuberculosis).

\section{References}

Aldwell FE, Keen DL, Parlane NA, Skinner MA, de Lisle GW, Buddle BM (2003a) Oral vaccination with Mycobacterium bovis BCG in a lipid formulation induces resistance to pulmonary tuberculosis in brushtail possums. Vaccine 22:70-76. doi:10.1016/S0264-410X(03)00539-5

Aldwell FE, Tucker IG, de Lisle GW, Buddle BM (2003b) Oral delivery of Mycobacterium bovis BCG in a lipid formulation induces resistance to pulmonary tuberculosis in mice. Infect Immun 71:101-108. doi:10.1128/IAI.71.1.101-108.2003

Aldwell FE, Baird MA, Fitzpatrick CE, McLellan AD, Cross ML, Lambeth MR, Buchan GS (2005) Oral vaccination of mice with lipid-encapsulated Mycobacterium bovis BCG: anatomical sites of bacterial replication and immune activity. Imm Cell Biol 83:549-553. doi:10.1111/j.1440-1711.2005.01369.x

Ali S, Jaffary KT, Zameer B, Gill ZJ (2009) Bovine TB zoonoses; a review. Pak J Sci 61:101-105

Ballesteros C, Gortázar C, Canales M, Vicente J, Lasagna A, Gamarra JA, Carrasco-García R, de la Fuente J (2009) Evaluation of baits for oral vaccination of European wild boar piglets. Res Vet Sci 86:388-393. doi:10.1016/j.rvsc.2008.09.003

Bean NJ, Mason JR (1995) Attractiveness of liquid baits containing natural and artificial sweeteners to white-tailed deer. J Wildl Manage 59:610-613

Boesi R, Biancardi C (2002) Diet of the Eurasian badger Meles meles (Linnaeus, 1758) in the Natural Reserve of Lago di Piano, northern Italy. Mamm Biol 67:120-125

Bonagura JD, Twedt DC (2008) Kirk's current veterinary therapy, 14th edn. Elsevier Saunders, Philadelphia

Campbell TA, Long DB (2009) Strawberry-flavored baits for pharmaceutical delivery to feral swine. J Wildl Manage 73:615619. doi:10.2193/2008-326

Clifton-Hadley RS, Wilesmith JW, Stuart FA (1993) Mycobacterium bovis in the European badger (Meles meles): epidemiological findings in tuberculous badgers from a naturally infected population. Epidemiol Inf 111:9-19

Cooper DW, Larsen E (2006) Immunocontraception of mammalian wildlife: ecological and immunogenetic issues. Reproduction 132:821-828

Corn JL, Mendez JR, Catalan EE (2003) Evaluation of baits for delivery of oral rabies vaccine to dogs in Guatemala. Am J Trop Med Hyg 69:155-158

Corner LAL, Costello E, Lesellier S, O'Meara D, Sleeman DP, Gormley E (2007) Experimental tuberculosis in the European, badger (Meles meles) after endobronchial inoculation of Mycobacterium bovis: I. Pathology and bacteriology. Res Vet Sci 83:53-62. doi:10.1016/j.rvse.2006.10.016

Corner LAL, Costello E, O'Meara D, Lesellier S, Aldwell FE, Singh M, Hewinson RG, Chambers MA, Gormley E (2010) Oral vaccination of badgers (Meles meles) with $\mathrm{BCG}$ and protective immunity against endobronchial challenge with Mycobacterium bovis. Vaccine 28:6265-6272. doi:10.1016/j.vaccine.2010.06.120

Craig WJ, Nguyen TT (1984) Caffeine and theobromine levels in cocoa and carob products. J Food Sci 49:302-303

Creekmore TE, Linhart SB, Corn JL, Whitney MD, Snyder BD, Nettles VF (1994) Field evaluation of baits and baiting strategies for delivering oral vaccine to mongooses in Antigua, West Indies. J Wildl Dis 30:497-505

Cross ML, Henderson RJ, Lambeth MR, Buddle BM, Aldwell FE (2009) Lipid-formulated BCG as an oral-bait vaccine for tuberculosis: vaccine stability, efficacy, and palatability to brushtail possums (Trichosurus vulpecula) in New Zealand. J Wildl Dis 45:754-765

Doran P, Carson J, Costello E, More SJ (2009) An outbreak of tuberculosis affecting cattle and people on an Irish dairy farm, following the consumption of raw milk. Ir Vet J 62:390-397

Estrada R, Vos A, de Leon RC (2001) Acceptability of local made baits for oral vaccination of dogs against rabies in the Philippines. BMC Infect Dis 1:19-23

Gans JH, Korson R, Cater MR, Ackerly DD (1980) Effects of shortterm and long-term theobromine administration to male dogs. Toxicol Appl Pharmacol 53:481-496

Gartrell BD, Reid C (2007) Death by chocolate: a fatal problem for an inquisitive wild parrot. New Zeal Vet J 55:149-151

Gormley E, Collins JD (2000) The development of wildlife control strategies for eradication of tuberculosis in cattle in Ireland. Tuberc Lung Dis 80:229-236

Gormley E, Costello E (2003) Tuberculosis and badgers: new approaches to diagnosis and control. J Appl Microbiol 94:80S-86S

Griffin JM, Williams DH, Kelly GE, Clegg TA, O'Boyle I, Collins JD, More SJ (2005) The impact of badger removal on the control of tuberculosis in cattle herds in Ireland. Prev Vet Med 67:237-266

Gunning OV (1950) Theobromine poisoning in ducks due to the feeding of cacao waste products. Br Vet J 106:31-32

Jansson DS, Galgan V, Schubert B, Segerstad CHA (2001) Theobromine intoxication in a red fox and a European badger in Sweden. J Wildl Dis 37:362-365

Jojola SM, Robinson SJ, Vercauteren KC (2007) Oral rabies vaccine (ORV) bait uptake by captive striped skunks. J Wildl Dis 43:97106

Lesellier S, Palmer S, Dalley DJ, Dave D, Johnson L, Hewinson RG, Chambers MA (2006) The safety and immunogenicity of Bacillus Calmette-Guerin (BCG) vaccine in European badgers (Meles meles). Vet Immunol Immunop 112:24-37. doi:10.1016/j. vetimm.2006.03.009

Lesellier S, Corner LAL, Costello E, Lyashchenko K, Greenwald R, Esfandiari J, Singh M, Hewinson RG, Chambers MA, Gormley E (2009) Immunological responses and protective immunity in BCG vaccinated badgers following endobronchial infection with Mycobacterium bovis. Vaccine 27:402-409. doi:10.1016/j.vaccine.2008.10.068

Linhart SB, Blom FS, Engeman RM, Hill HL, Hon T, Hall DI, Shaddock JH (1994) A field-evaluation of baits for delivering oral rabies vaccines to raccoons (Procyon lotor). J Wildl Dis 30:185-194

McDowell A, McLeod BJ, Rades T, Tucker IG (2006) Application of pharmaceutical drug delivery for biological control of the common brushtail possum in New Zealand: a review. Wildl Res 33:679-689

Marsh RE (1988) Bait additives as a means of improving acceptance by rodents. EPPO Bull 18:195-202. doi:10.1111/j.13652338.1988.tb00366.x

Matter HC, Kharmachi H, Haddad N, ben Youssef S, Sghaier C, ben Khelifa R, Jemli J, Mrabet L, Meslin FX, Wandeler AI (1995) Test of three bait types for oral immunization of dogs against rabies in Tunisia. Am J Trop Med Hyg 52:489-495 
More SJ, Good M (2006) The tuberculosis eradication programme in Ireland: a review of scientific and policy advances since 1988. Vet Microbiol 112:239-251. doi:10.1016/j.vetmic.2005.11.022

Morgan DR (1990) Behavioural response of brushtail possums, Trichosurus vulpecula, to baits used in pest control. Aus Wildl Res 17:601-613

Morgan DR, Innes J, Frampton CM, Woolhouse AD (1995) Responses of captive and wild possums to lures used in poison baiting. New Zeal J Zool 22:123-129

Morris RS, Pfeiffer DU, Jackson R (1994) The epidemiology of Mycobacterium bovis infections. Vet Microbiol 40:153-177

Naranjo V, Gortazar C, Vicente J, de la Fuente J (2007) Evidence of the role of European wild boar as a reservoir of tuberculosis due to Mycobacterium tuberculosis complex. Vet Microbiol 127:1-9. doi:10.1016/j.vetmic.2007.10.002

Novakofski J, Brewer MS, Mateus-Pinilla N, Killefer J, McCusker RH (2005) Prion biology relevant to bovine spongiform encephalopathy. J Anim Sci 83:1455-1476

O'Keeffe JJ (2006) Description of a medium term national strategy towards eradication of tuberculosis in cattle in Ireland. In: More SJ (ed) Biennial report, 2004-2005. Centre for veterinary epidemiology and risk analysis, TB diagnostics and immunology research centre, Badger Vaccine Project. University College Dublin, Ireland, pp 101-105

Pouwels PH, Leer RJ, Shaw M, Heijne den Bak-Glashouwer M-J, Tielen FD, Smit E, Martinez B, Jore J, Conway PL (1998) Lactic acid bacteria as antigen delivery vehicles for oral immunization purposes. Int J Food Microbiol 41:155-167

Roscoe DE, Holste WC, Sorhage FE, Campbell C, Niezgoda M, Buchanan R, Diehl D, Niu HS, Rupprecht CE (1998) Efficacy of an oral vaccinia-rabies glycoprotein recombinant vaccine in controlling epidemic raccoon rabies in New Jersey. J Wildl Dis $34: 752-763$

Schmitt SM, Fitzgerald SD, Cooley TM, Bruning-Fann CS, Sullivan L, Berry D, Carlson T, Minnis RB, Payeur JB, Sikarskie J (1997) Bovine tuberculosis in free-ranging white-tailed deer from Michigan. J Wildl Dis 33:748-758

Slate D, Algeo TP, Nelson KM, Chipman RB, Donovan D, Blanton JD, Niezgoda M, Rupprecht CE (2009) Oral rabies vaccination in North America: opportunities, complexities, and challenges. PLoS Negl Trop Dis 3:e549. doi:10.1371/journal.pntd.0000549

Smith GC, Woods JA (2007) Acceptance of baits, designed to carry oral rabies vaccines, by foxes in Britain. Int J Pest Manage 53:323-328. doi:10.1080/09670870601185222

Southey AK, Sleeman DP, Gormley E (2002) Sulfadimethoxine and rhodamine B as oral biomarkers for European badgers (Meles meles). J Wildl Dis 38:378-384

Steelman HG, Henke SE, Moore GM (2000) Bait delivery for oral rabies vaccine to gray foxes. J Wildl Dis 36:744-751

Stolzenburg HW, Howard VW (1989) Activation of liquid bait devices by coyotes in southern New Mexico. Wildl Soc Bull 17:306-312

Takeuchi M (2007) Avoidance of badger (Meles meles) damage to a small strawberry field. Jap J Appl Entomol Zool 51:187-196. doi:10.1303/jjaez.2007.187

Tassou CC, Drosinos EH, Nychas GJE (1997) Weak antimicrobial effect of carob (Ceratonia siliqua) extract against food-related bacteria in culture media and model food systems. World $\mathrm{J}$ Microbiol Biotech 13:479-481

Tompkins DM, Ramsey DSL, Cross ML, Aldwell FE, de Lisle GW, Buddle BM (2009) Oral vaccination reduces the incidence of tuberculosis in free-living brushtail possums. Proc Roy Soc B Biol Sci 276:2987-2995. doi:10.1098/rspb.2009.0414 